\title{
EFFECT OF VEILLONELLA INFANTIUM ON BIOFILM FORMATION OF ORAL STREPTOCOCCUS
}

\author{
RATNA RAMADHANI, ARIADNA ADISATTYA DJAIS*, BOY MUCHLIS BACHTIAR
}

Department of Oral Biology, Faculty of Dentistry, Universitas Indonesia, Jakarta 10430, Indonesia. Email: ariedjais26@gmail.com Received September 20, 2018, Revised and Accepted Desember 22, 2018

\begin{abstract}
Objective: Therefore, we aimed in this study to evaluate the effect of Veillonella infantium on the biofilm formation of oral Streptococcus species.

Methods: Dual-species biofilm was formed between V. infantium and oral Streptococcus using the wire method, and it was then incubated at $37^{\circ} \mathrm{C}$ under anaerobic condition for 5 days. Biofilm formation was determined by measuring the DNA concentration. Single species biofilm of oral Streptococcus was generated under the same conditions and was used as a control group.
\end{abstract}

Result: The presence of $V$. infantium decreased the biofilm formation of Streptococcus mutans, where, in contrast, the formation of biofilm in Streptococcus sanguinis was increased by the presence of $V$. infantium $(\mathrm{p}<0.05)$.

Conclusion: The presence of V. infantium decreased the biofilm formation of S. mutans.

Keywords: Biofilm, Veillonella infantium, Streptococcus mutans, Streptococcus sanguinis.

(C) 2019 The Authors. Published by Innovare Academic Sciences Pvt Ltd. This is an open access article under the CC BY license (http://creativecommons. org/licenses/by/4. 0/) DOI: http://dx.doi.org/10.22159/ijap.2019.v11s1.18458

\section{INTRODUCTION}

More than 700 bacterial species have been identified as existing in the oral cavity [1]. Interactions between those microorganisms are found biofilm on the dental surface, which is known as dental plaque. The presence of biofilm in the oral cavity could impair oral health [2]. Approximately $65 \%$ of bacterial infectious disease is associated with bacterial biofilm. Biofilm plays a role on the development of oral infectious disease, such as caries [3].

Biofilm is a community of bacteria that is embedded in an extracellular polymeric matrix and is attached to a substratum or surfaces, or each bacterium of the community is attached to each other [4]. Biofilm formation consists of several stages initiated by the attachment of an initial colonizer such as Streptococcus species, on pellicle-coated dental surfaces, followed by an early colonizer such as Veillonella species. After the settlement of the early colonizer, the maturation process occurs followed by dispersion of mature cells to other surfaces to begin the cycle of biofilm formation $[3,5]$.

Streptococcus species is an initial colonizer in the biofilm formation and is found on $60-90 \%$ of subgingival plaque in the first $24 \mathrm{~h}$ of bacterial colonization [6]. Streptococcus catabolizes carbohydrates into shortchain organic acids, such as lactic acid and pyruvic acid [7]. The acid product of Streptococcus can decrease the $\mathrm{pH}$ in the oral cavity, leading to the demineralization in the formation of caries. The end product of Streptococcus could be utilized as the nutrient source to other bacteria such as Veillonella. Oral Veillonella is known as an early colonizer that interacts with Streptococcus in the early stage of biofilm formation [8].

Oral Veillonella is a Gram-negative, strictly anaerobe constituting 5\% of initial dental plaque biomass [9]. Seven species of Veillonella have been identified in the oral cavity: Veillonella atypica, Veillonella denticariosi, Veillonella dispar, Veillonella Parvula, Veillonella rogosae, Veillonella tobetsuensis, and Veillonella infantium [10-12]. V. infantium was identified from the T11011-4 strain isolated from the biofilm existing in 10-year-old children in Thailand who all had good oral hygiene status. The colony was round in shape with a smooth surface, opaque grayish white, $0.5-2 \mathrm{~mm}$ in diameter, without hemolysis on brain heart infusion (BHI) blood agar, and showed basic fuchsin decolorization on Veillonella selective media [12].

It has been reported that six oral Veillonella species such as V. atypica, $V$. denticariosi, V. dispar, V. parvula, V. rogosa, and V. tobetsuensis affected the formation of four oral Streptococcus biofilm, Streptococcus mutans, Streptococcus salivarius, Streptococcus sanguinis, and Streptococcus gordonii, synergistically and antagonistically [9]. However, the effect of $V$. infantium on the biofilm formation of oral Streptococcus had not been investigated.

\section{METHODS}

\section{Bacterial strains and growth conditions}

S. mutans ATCC 25175 and S. sanguinis 10556 were cultured on TY agar (TY Bacto Tryptic Soy Broth and Bacto Yeast Extract) under anaerobic conditions $\left(\mathrm{N}_{2}: \mathrm{CO}_{2}: \mathrm{H}_{2}, 80: 10: 10\right)$ at $37^{\circ} \mathrm{C}$ for 3 days. V. infantium T11011-4 was cultured on BHI blood agar (bacto BHI) supplemented with $5 \%$ defibrinated sheep blood and $2 \%$ sodium lactate under anaerobic conditions at $37^{\circ} \mathrm{C}$ for 5 days.

\section{Biofilm formation using the wire method}

Biofilm formation was performed using commonly utilized cobaltchrome alloy wires that were $0.9 \mathrm{~mm}$ in diameter and $9 \mathrm{~cm}$ in length (TECHNOFLEX, Rocky Mountain Morita Corporation, Tokyo, Japan). The wires were sterilized in an autoclave after affixing a rubber plug and flexible tubing (TYGON Saint-Gobain, Malvern, PA, USA) to the wire ends.

About $1 \mathrm{~mL}$ of a suspension of each culture of Streptococcus spp., the turbidity of which was determined by measuring the absorption at $\mathrm{OD}_{660}: 0.5\left(5 \times 10^{7} \mathrm{CFU} / \mathrm{ml}\right)$, was inoculated into a test tube of $4 \mathrm{ml}$ of BHI broth containing $1 \%$ sucrose. Next, a wire treated with artificial saliva (Saliveht; TEIJIN, Osaka, Japan), was inserted into the test tube as a base for biofilm formation. After incubation under anaerobic conditions at $37^{\circ} \mathrm{C}$ for 1 day, the wire with the Streptococcus biofilm was transferred into suspensions of $V$. infantium cultures, the turbidity of which was also been determined by measuring the absorption at $\mathrm{OD}_{660}: 0.5\left(0.5 \times 10^{7} \mathrm{CFU} / \mathrm{ml}\right)$ and test tubes containing the same media were supplemented with $2 \%$ sodium lactate. The cocultures were 
Table 1: DNA concentration of dual-species biofilm formation of $S$. mutans, $S$. sanguinis, and V. infantium and control group on days 1, 3, and $5(\mathrm{ng} / \mu \mathrm{l})$

\begin{tabular}{|c|c|c|c|c|c|c|}
\hline \multirow{2}{*}{$\begin{array}{l}\text { Bacterial Combination } \\
\text { of Biofilm }\end{array}$} & \multicolumn{6}{|c|}{ Mean \pm standard deviation of DNA concentration $(\mathrm{ng} / \mu \mathrm{l})$} \\
\hline & Control day 1 & S+VI day 1 & Control day 3 & S+VI day 3 & Control day 5 & S+VI day 5 \\
\hline S. mutans $+V$. infantium & $0.217 \pm 0.050$ & $0.213 \pm 0.101$ & $0.322 \pm 0.070$ & $0.458 \pm 0.162$ & $0.736 \pm 0.408$ & $0.623 \pm 0.206$ \\
\hline S. sanguinis $+V$. infantium & $0.021 \pm 0.030$ & $1.163 \pm 0.505$ & $0.116 \pm 0.164$ & $1.902 \pm 0.625$ & $0.364 \pm 0.090$ & $3.548 \pm 2.256$ \\
\hline
\end{tabular}

S. mutans: Streptococcus mutans, V. infantium: Veillonella infantium, S. sanguinis: Streptococcus sanguinis

incubated in anaerobic conditions at $37^{\circ} \mathrm{C}$ for 1 day to generate mixed biofilms containing Streptococcus spp. and V. infantium. The media in the test tubes were replaced with fresh media every day for 5 days. Biofilm containing S. mutans and S. sanguinis alone was generated on wires under the same conditions and was used as a control.

\section{DNA extraction and quantification}

The biofilms on the wires were removed using flexible tubing and were collected in a sterilized tube. DNA was extracted using phenolchloroform and ethanol precipitation. Briefly, biofilm cells were dispersed with BioMasher after mixing with saline EDTA. Sodium dodecyl sulfate (SDS) $20 \%$ was added to the tube and then heated on HeatLock at $60^{\circ} \mathrm{C}$ for $10 \mathrm{~min}$. Phenol-chloroform was added and homogenized with vortex, and the tube was centrifuged at $4^{\circ} \mathrm{C}$ and $15,000 \mathrm{rpm}$ for $5 \mathrm{~min}$. The aqueous layer was collected and moved to another tube using an Eppendorf pipette. Proteinase- $\mathrm{K} 50 \mu \mathrm{g} / \mathrm{ml}$ and $0.5 \%$ SDS were added to the tube. The tube was then heated at $56^{\circ} \mathrm{C}$ for $1 \mathrm{~h}$. Ethanol precipitation was performed by adding $99.5 \%$ ethanol, $5 \mathrm{M}$ sodium chloride, and glycogen $10 \mu \mathrm{g} / \mathrm{ml}$ to the tube containing aqueous phase, and the tube was stored at $4{ }^{\circ} \mathrm{C}$ overnight. The next day, the tube was centrifuged at $4^{\circ} \mathrm{C}$ and $8500 \mathrm{rpm}$ for $10 \mathrm{~min}$. The supernatant was removed and the formed pellet was dissolved by adding TE solution. The genomic DNA was stored at $-20^{\circ} \mathrm{C}$ until further analysis. The DNA concentration of each fraction was determined with a Qubit Fluorometer using Qubit dsDNA BR Assay Kit (Invitrogen), according to the manufacturer's instructions. At least $2 \mu \mathrm{l}$ of each sample was used to measure DNA concentration.

\section{Statistical analysis}

The experiment was conducted in triplicate, and the obtained data were expressed as mean \pm standard deviation (SD). Statistical significance was determined using a parametric independent $\mathrm{t}$-test and non-parametric Mann-Whitney U-test for the comparison between the control and experimental groups on days 1,3 , and 5 of incubation. $p<0.005$ was considered to be statistically significant.

\section{RESULTS}

Table 1 and Figs. 1 and 2 show the amount of biofilm formed by S. mutans and $S$. sanguinis with $V$. infantium after 5 days, including control, as determined from the results of DNA concentration measurement. The combination of $V$. infantium and $S$. mutans decreased the amount of biofilm formation after 5 days of incubation as compared with the control group. Alternatively, the presence of $V$. infantium increased the amount of the biofilm formation in combination with S. sanguinis on days 1,3 , and 5 of incubation as compared with control group.

Biofilm formed by $S$. mutans in combination with $V$. infantium was slightly lower than that in the control group on day 1 and then increased on day 3 of incubation and was higher than the amount of biofilm in the control group. A lower amount of biofilm formed by $S$. mutans in combination with $V$. infantium was observed after 5 days of incubation compared with the control group, although it was not statistically significant $(\mathrm{p}>0.05)$. When $V$. infantium was combined with $S$. sanguinis, biofilm formation on days 1,3 , and 5 of incubation was significantly higher than biofilm formation in the control groups with $p=0.003,0.004$, and 0.002 , respectively. An increasing amount of biofilm formation over time was also observed in the combination of S. sanguinis and V. infantium on days 1, 3, and 5 of incubation.

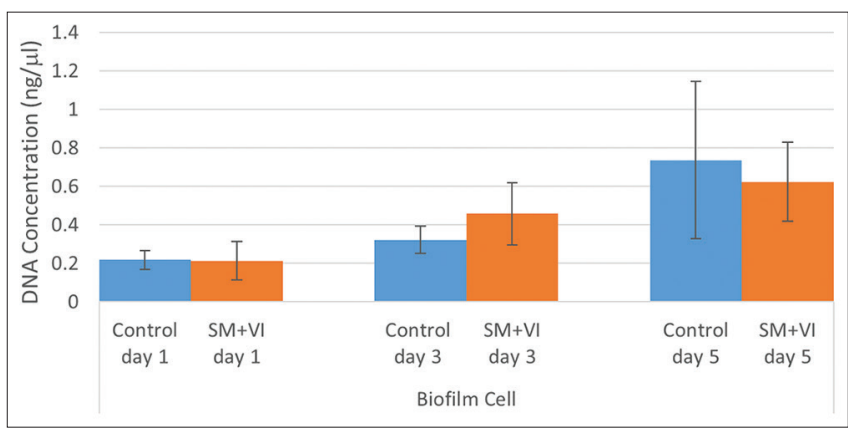

Fig. 1: Dual-species biofilm formation of Streptococcus mutans and Veillonella infantium dual species compared with S. mutans single species (control) based on DNA concentration

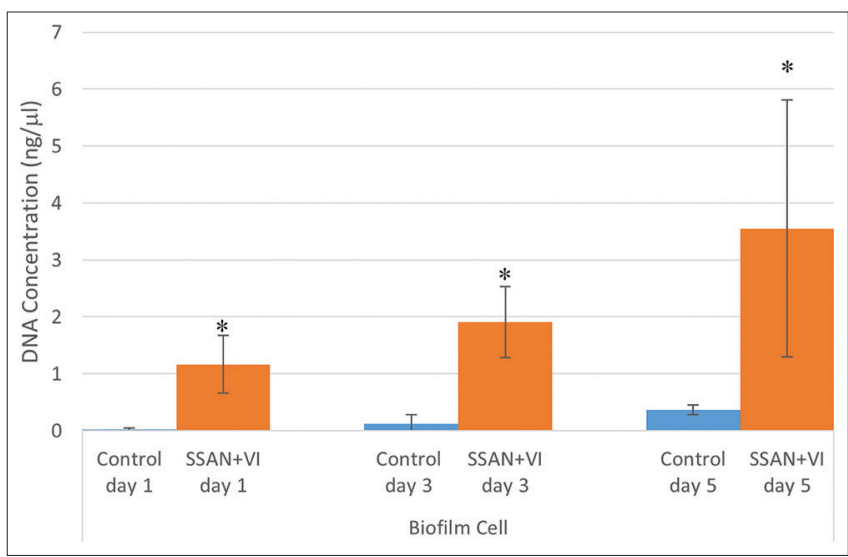

Fig. 2: Dual-species biofilm formation of Streptococcus sanguinis and Veillonella infantium compare with $S$. sanguinis single species (control) based on DNA concentration

\section{DISCUSSION}

The previous study showed that six species of oral Veillonella species combined with four oral Streptococcus species synergistically and antagonistically affected the formation of dual-species biofilm [9]. Other experiments have shown that oral Streptococcus interacted with $V$. atypica through the mediation of adhesins [13]. In addition, one of the Streptococcus transcription factors, catabolite control protein A, is needed for interaction between S. gordonii and V. atypica [14]. In this study, the presence of $V$. infantium was able to decrease the biofilm formation of $S$. mutans. The presence of $V$. infantium was conversely able to increase the biofilm formation of $S$. sanguinis $(\mathrm{p}<0.05)$. V. infantium is shown to have an antagonistic and synergistic effect on the biofilm formation of S. mutans and S. sanguinis, respectively.

Coaggregation and coadhesion are mechanisms of bacterial interaction [15]. A previous study has shown that V.parvula that was isolated from subgingival plaque coaggregated with S.sanguinis. However, in the same study, V.parvula was found not coaggregated with S.salivarius [16]. Another study has shown that $V$. rogosae, which is frequently isolated from tongue biofilm, coaggregated with S. salivarius [17]. Based on these findings, it could be stated that the coaggregation characteristic among 
oral Veillonella species showed a selective interaction of compatible partners for biofilm formation. In this study, the combination of the dual species of $S$. sanguinis and $V$. infantium demonstrated a higher biofilm formation compared with the combination of $S$. mutans and $V$. infantium.

The presence of $V$. infantium resulted in higher and lower amounts of biofilm formation by $S$. mutans after 3 and 5 days of incubation, respectively, compared with the control group, which suggests that $V$. infantium would affect the amount of biofilm formation of $S$. mutans as the time of incubation increased. In this study, the presence of $V$. infantium increased the amount of biofilm formation of $S$. sanguinis. Another study has shown that the presence of $V$. atypica, $V$. denticariosi, $V$. rogosae, and $V$. tobetsuensis decreased the amount of biofilm formation of $S$. sanguinis. In the same study, the presence of $V$. parvula increased the amount of biofilm formed by $S$. sanguinis [9]. These results might suggest that $V$. infantium shares a similar characteristic with $V$. parvula in the formation of biofilm combined with $S$. sanguinis, synergistically. S.sanguinis was shown in order study to produce hydrogen peroxide, which was found to inhibit the growth of S.mutans [18]. These findings might suggest a similar antagonistic interaction between $S$. sanguinis and $V$. infantium on $S$. mutans.

\section{CONCLUSION}

The presence of $V$. infantium decreased the biofilm formation of $S$. mutans. However, an increasing amount of biofilm formation between $V$. infantium and $S$. sanguinis was observed as incubation time increase suggesting an antagonistic interaction between $V$. infantium and $S$. mutans and a synergistic interaction between $V$. infantium and $S$. sanguinis. Further studies are needed to evaluate the proportion of each species and the mechanism of interactions. Furthermore, an investigation of the effect of $V$. infantium on the biofilm formation of $S$. mutans and S. sanguinis in vivo is needed.

\section{ACKNOWLEDGMENT}

The authors are grateful to Professor Nakazawa Futoshi Ph.D., Mashima Izumi Ph.D., Miyakawa Hiroshi Ph.D., and Fujita Mari Ph.D., for the kind help and support throughout this study. The publication of this manuscript is supported by the Directorate of Research and Community Engagement of the Universitas Indonesia.

\section{CONFLICTS OF INTEREST}

There are no conflicts of interest to declare.

\section{REFERENCES}

1. Huang R, Li M, Gregory RL. Bacterial interactions in dental biofilm. Virulence 2011;2:435-44.
2. Kolenbrander PE, Andersen RN, Blehert DS, Egland PG, Foster JS, Palmer RJ Jr., et al. Communication among oral bacteria. Microbiol Mol Biol Rev 2002;66:486-505, table of contents.

3. Jamal M, Ahmad W, Andleeb S, Jalil F, Imran M, Nawaz MA, et al. Bacterial biofilm and associated infections. J Chin Med Assoc 2018;81:7-11.

4. Costerton JW, Lewandowski Z, Caldwell DE, Korber DR, Lappin-Scott HM. Microbial biofilms. Annu Rev Microbiol 1995; 49:711-45.

5. Lin NJ. Biofilm over teeth and restorations: What do we need to know? Dent Mater 2017;33:667-80.

6. Mager DL, Ximenez-Fyvie LA, Haffajee AD, Socransky SS. Distribution of selected bacterial species on intraoral surfaces. J Clin Periodontol 2003;30:644-54.

7. Deibel RH, Seeley HW. Gram Positive Cocci. In: Krieg NR, Holt JG, editors. Bergey's Manual of Systematic Bacteriology. Vol. 1. Baltimore: William and Wilkins; 1984. p. 680-5.

8. Periasamy S, Kolenbrander PE. Central role of the early colonizer Veillonella sp. In establishing multispecies biofilm communities with initial, middle, and late colonizers of enamel. J Bacteriol 2010; 192:2965-72.

9. Mashima I, Nakazawa F. The influence of oral Veillonella species on biofilms formed by Streptococcus species. Anaerobe 2014;28:54-61.

10. Byun R, Carlier JP, Jacques NA, Marchandin H, Hunter N. Veillonella denticariosi $\mathrm{sp}$. Nov. isolated from human carious dentine. Int J Syst Evol Microbiol 2007;57:2844-8.

11. Arif N, Do T, Byun R, Sheehy E, Clark D, Gilbert SC, et al. Veillonella rogosae sp. Nov. an anaerobic, gram-negative coccus isolated from dental plaque. Int J Syst Evol Microbiol 2008;58:581-4.

12. Mashima I, Liao YC, Miyakawa H, Theodorea CF, Thawboon B, Thaweboon $\mathrm{S}$, et al. Veillonella infantium sp. Nov. an anaerobic, gramstain-negative coccus isolated from tongue biofilm of a Thai child. Int J Syst Evol Microbiol 2018;68:1101-6.

13. Hughes CV, Roseberry CA, Kolenbrander PE. Isolation and characterization of coaggregation-defective mutants of Veillonella atypica. Arch Oral Biol 1990;35 Suppl:123S-5S.

14. Johnson BP, Jensen BJ, Ransom EM, Heinemann KA, Vannatta KM, Egland KA, et al. Interspecies signaling between Veillonella atypica and Streptococcus gordonii requires the transcription factor ccpA. J Bacteriol 2009;191:5563-5.

15. Foster JS, Kolenbrander PE. Development of a multispecies oral bacterial community in a saliva-conditioned flow cell. Appl Environ Microbiol 2004;70:4340-8.

16. Hughes CV, Kolenbrander PE, Andersen RN, Moore LV. Coaggregation properties of human oral Veillonella spp.: Relationship to colonization site and oral ecology. Appl Environ Microbiol 1988;54:1957-63.

17. Mashima I, Kamaguchi A, Nakazawa F. The distribution and frequency of oral Veillonella spp. In the tongue biofilm of healthy young adults. Curr Microbiol 2011;63:403-7.

18. Giacaman RA, Torres S, Gómez Y, Muñoz-Sandoval C, Kreth J. Correlation of Streptococcus mutans and Streptococcus sanguinis colonization and ex vivo hydrogen peroxide production in carious lesion-free and high caries adults. Arch Oral Biol 2015;60:154-9. 